\title{
Exploring the Characteristics of Healthy Lifestyle Campaign on Social Media: A Case Study on FIT Malaysia
}

\author{
SUFFIAN HADI AYUB \\ Sunway University, Malaysia \\ NURZIHAN HASSIM \\ Taylor's University, Malaysia \\ AZIZUL HALIM YAHYA \\ MASSILA HAMZAH \\ MOHD. ZAMRI ABU BAKAR \\ Universiti Teknologi MARA
}

\begin{abstract}
Through the establishment of FIT Malaysia, the Malaysian Ministry of Youth and Sports (MOYS) aimed to ensure the adoption of healthy lifestyles by all Malaysians particularly youth, with initiatives to provide a variety of sports and fitness activities. This paper discusses the characteristics of the healthy lifestyle campaign by MOYS in spearheading the promotion of healthy living among youth after joining the social media bandwagon, with consideration of the time spent online by this targeted community. The study is significant to ensure that MOYS not only organises, but most importantly, utilises the most appropriate means in reaching the intended youth audiences. Through in-depth interviews with policy makers and implementers at MOYS, it was discovered that the characteristics of campaign management were not in line with social media characteristics and this has resulted in the superficial understandings of the success rate of promoting FIT Malaysia in Facebook and Twitter. This further highlighted the needs for the stakeholders to possess holistic knowledge on the social media realm as well as appropriate tools and sufficient budget to implement healthy lifestyle campaigns on social media. From this perspective, the paper provides in-depth discussions of health promotion from two aspects; the characteristics of campaign and how it can be synthesised with social media characteristics to reach out to youth and their healthy lifestyle in Malaysia through social media.
\end{abstract}

Keywords: Youth, social media, health promotion, health communication, campaign.

\section{INTRODUCTION}

Rapid growth of the internet has created exponential communication opportunities between firms and their constituents. Online communities have seen individuals socialise with likeminded peers from different backgrounds and share content through multitudes of web and mobile applications seamlessly in a borderless environment (Hajli, 2013). Such engagement on social media platforms like Facebook and Twitter have enabled access to information that are built around recommendations of others, thus removing the need for physical presence (Mueller et al, 2011). Further to this, electronic word-of-mouth (eWOM) among online audiences offers great value to firms and brand contexts where stimuli of user-generated content (UGC) trigger emotions and cognitive response through elements that increase the likelihood of information pass-along, engagement and behavioural responses towards a specific action of a firm (Kim \& Johnson, 2016). Consequently, this enhances the popularity of 
firms on social media through their shared values and gains trust from constituents. Aside from marketing and creating a brand position for a firm, these digital touchpoints are imperative in affecting the allegiance of online communities towards positive ideologies and campaign agendas that involve behavioural change as well as their physical well being.

This is particularly evident among digital natives who are born into the convenience of communication technology. Youths, who range from adolescents to young adults of mostly high-school and university students; are most adept when it comes to the use of social media within a "networked society" that provided virtual communication channels that could fulfil their personal interests in learning and socialising (Calin \& Birsanescu, 2017; Fernández-Cruz \& Fernández-Díaz, 2016; Castells, 2011). Heverly (2008) posited that due to their increased dependency on social media, these platforms have become pertinent to establish subjective norms and sustain their relationships to the extent that the use becomes immersive and to some points, addictive. Subsequently, youths play an active and important role; where they interchangeably become producers and receivers of information through the sharing functions of many applications and websites.

In Malaysia, a census by Department of Statistics affirmed Malaysia as one of the more developing countries that have had the highest internet penetration at $76.9 \%$ in comparison to other countries in Southeast Asia (Malaysian Communications and Multimedia Commission, 2017). The youth population has increased significantly which clearly illustrates their contribution to the national economy and socio-economy. Defined as those aged between 15 to 40 years by the National Youth Development Policy of Malaysia (NYDP), it was established that that the focus for any youth development programmes and activities Malaysia should be aimed at young people within the age range from 18 to 25 years old (Economic and Social Commission for Asia and The Pacific, 2002).

With regards to this, the FIT Malaysia programme was introduced by the Ministry of Youth and Sports (MOYS) to increase awareness on the importance of a healthy lifestyle among Malaysians, particularly the youths. This initiative was intended to potentially pave the way for the country to become a true sporting nation. Through a community-centric approach, FIT Malaysia emphasises on fitness-related activities that can be done at the convenience of the people and does not involve any cost. FIT Malaysia focuses on four main activities to ensure public participation which are running, cycling, martial arts and fitness programmes. Apart from having its own website and mobile applications, FIT Malaysia uses social media to promote healthy living and programmes planned for the initiative; namely Facebook, Twitter, and Instagram.

A study by Baboo et al. (2015) highlighted that social media increased the need for young Malaysians to engage in relationships, learning and adjust their perceptions on current issues as well manage their anticipation. However, the impact of social campaigns by corporate and authoritative bodies online were found less than fruitful. The government implementation of the 1Malaysia concept saw respondents having little to no understanding of what comprised of the national unity and social integration concept were also evident in their inability to associate with 1Malaysia-based events and programmes initiated by ministries of the government, three years into its implementation (Sunway University, 2015). The discussions further saw a downtime on the topic, showing the decrease of interest among youth social media users despite them being more critical about the campaign early in its inception. The major foundation of work on what young people share information in what 
they do is not arbitrary or dictated by the social media sites that they frequent, rather, the platforms need to tweak their features to suit youth user preferences. Boyd (2014) also revealed that young people are only concerned about making a good impression to peers by revealing their norms, cultural dynamics as a by-product, foundational to the identity of the youth that are implicated in their online discourse. Similarly, Boyd continued to deliberate that implicit information is presented but the skills of reading explicit content of the message given by others plays a major role in shaping their perceptions as well as how they are perceived by others.

Henceforth, the information-seeking behaviour of youths are crucial for governing bodies to chart best approaches in communicating health-related information towards the same target group. In relations to the FIT Malaysia programme, it is imperative to evaluate the strategies and effort implemented by relevant stakeholders in communicating to the youth on the aforementioned digital platforms considering that youths belonging to these age groups spend more time online. Similarly, the extent of social media presence of relevant organisations should also be observed. As the social media bandwagon provides the outlet for youths to explore and express themselves, it also becomes a learning experience that would affect their attitudes. In short, this study seeks to examine the extent of social media characteristics used in creating awareness on healthy lifestyle by MOYS through FIT Malaysia and how it could potentially impact the targeted community of youths.

\section{LITERATURE REVIEW}

A study by Gardner and Davis (2013) on "The App Generation" detailed an analysis that established the concept of "practical credentialists" among youths of today who are more centred on manning their daily lives and relationships than focus on specific objectives, agenda or ideology. The study had found that $86 \%$ of youths in the pre-Internet era from the 1960 s-1980s are driven to serve a purpose in life or chase after a goal or dream beneficial to themselves or society but in 2012, youths that agree to this notion pale in comparison at only $46 \%$. The uses of social media today are more individualistic and the interconnectedness between youths who are implicated are concerned with being able to have their own voice of moral freedom that allows them to shape their persona while having less risk of sacrificing their personal means to an end of other parties' interests. At the same time, from the aspect of media saturation, youths and the frequency of their media use depend on the affordance of their modality or discourse (Sundar \& Limperos, 2013). Having more channels of access to social media whether through their smartphones, tablets or computers, youths crave to be seen as more superior than one another in their interactions with peers. Hence, devices and multiple interfaces are utilised in order to not zone into the "fear of missing out" or FOMO, where being socially excluded in their virtual interactions due to actual or potential distance would result in what is called "social pain", that is unpleasant and would have severe consequences to online and even offline relationships (Lai et al., 2016). Additionally, online behaviours that concern youth membership and relationships with one another on social media, such as "following" and "unfollowing" or reposting information creates a less hostile environment that allows a share of voice among youths despite however meek, shy or unfavourable they may be in real life (Yuksel \& Labrecque, 2016). In concern of the FIT Malaysia campaign, the data or content is seen as unobtrusive as social media users have the 
upper hand to "opt-in" or "opt-out" regardless of the background of youths that share or forward the beneficial information to peers. This gives more empowerment to youths in sharing and reinforcing good intentions and ideas to their peers.

In recent years, changes in social media have seen how firms and audiences interact with one another. Selective exposure is something to be considered by marketers, especially by firms of authoritative bodies on a global scale as social media users themselves are able to curate and tick preferences of what information or content that they want to see, particularly youth who have highly individualistic needs (Newman et al., 2017, p.44) This includes changing settings on their social media platforms so news from a specific organisation will be reduced, deleted or blocked and sustain being "friends" or "followers" of specific corporate social media accounts. Further, according to Newman et al. (2017), barely $36 \%$ of social media youths view a corporate social media account to follow up on updates and news of the organisation. However, a recent report by the Malaysian Communications and Multimedia Commission (MCMC) and Institute for Health Behavioural Research (IPTK) of Ministry of Health Malaysia (MOH), 94\% of Malaysian Internet users relied on online sources to seek information on health information, specifically on healthcare tips, treatment methods and medications - most commonly, the users sought information on symptoms and diseases (Malaysian Communications and Multimedia Commission, 2017). The evidence suggests that there needs to be a reconciliation and intervention in terms of information characteristics on the social media platforms that are used by firms, with the criteria set by Internet users specifically the youth majority who are active in looking for health content that benefit them on a personal level. With the case of Fit Malaysia, it is an even bigger window of penetration with the ease of its features that are especially convenient for youths who are digital media savvy.

Prior to this, social networking and communication convergence was studied by Mayfield (2011) who listed five definitive social media characteristics; 1) participation, 2) openness, 3) connectedness, 4) community, and 5) conversation. Mayfield had posited that participation in social media blurs the line between media and audiences as it allows for simultaneous contributions and feedback from any interested party; whether actively or passively. The factors that contribute to these include "Openness", meaning that the feedback and participation are continuously open to encourage audiences to vote, post comments and share any information. Openness also suggests that any barriers depriving the audiences to access and use the content is rather uncommon and unfavourable. "Connectedness", on the other hand, states how social media audiences utilise various other sites and resources available to create linkage and possible networking across demographics. "Community" is the greater effect of connectedness where it creates a united atmosphere within online communities. Audiences are physically and geographically separated from each other but commune for shared interests. Finally, "Conversation" according to Mayfield, is the two-way communication that social media presents to its audiences that differ from other traditional media where feedback is often delayed or none at all.

From the standpoint of social media communication practiced by firms, Alaniz (2012) outlined eight important elements as a checklist to ensure an effective public relations (PR) planning and promotions among firms; situation analysis, objectives, strategy, tactics, audience, timeline, budget, and evaluation. These eight elements cover the essentials for embedded in the traditional approach for PR planning such as RACE (research, action, 
communication, evaluation), PIE (planning, implementation, evaluation). These planning are the embodiment of any legitimate characteristics of PR programme which at all times must voluntary in nature (freewill), provide mutual benefit for sender and receiver, and finally a multidisciplinary approach that contribute to the success of the campaign itself. Moreover, strategic campaigns must focus on developing a good fit between an organisation's activities and the demand of the environment around it.

As explained by Businesstopia (2017), social marketing implemented online tries to understand social and psychological factors which bring resistance to change in society, increase acceptability, response and practice of any social idea for their target group. Its ultimate aim is to create an environment for social intervention to take place. This means that awareness is the key element in social marketing theory where people know the alternatives that they can adopt so that they are benefited in the future. When different channels are used to create awareness, people come to know about new things. In other words, awareness is the first step to change and this is the most crucial part in social intervention; through cognitive awareness.

\section{METHODOLOGY}

This present study performed qualitative content analysis (QCA) on data collected from indepth interviews with MOYS officials that were responsible for the promotion of FIT Malaysia in social media. The method was selected to examine social media characteristics and discourse involving officials and efforts on highlighting FIT Malaysia to targeted youth communities in Malaysia. QCA was also selected as it can be applied to identify themes beyond conventional media and have progressed beyond the analysis of hardcopy text (Hassim, 2017). The data collection applied purposive sampling where it was determined that the criteria of participants must be policymakers or officers responsible for implementation and administration of FIT Malaysia social media platforms. With that said, two relevant departments were identified; which were the Department of Youth and Sports (DYS) and Corporate Communication Unit (CCU) from MOYS. At DYS, the in-depth interviews were conducted with two participants involved in policymaking and the implementation of FIT Malaysia. Meanwhile at CCU, the in-depth interviews involved three participants ranging from decision makers to social media administrators.

Subsequently, the interviews conducted had applied a deductive approach using predetermined themes derived from the social media characteristics that were posited by Mayfield (2011) to guide the discussion. In addition, the interview questions were based on the media effects theory to probe into the usage of social media in the promotion of FIT Malaysia. A total of 38 semi-structured questions were formulated to address the research objectives in creating awareness on FIT Malaysia initiatives to the discerning youths. Preliminary data and previous studies outlined in the literature review, focusing on social media trends and its role in creating awareness and disseminating information to youths in Malaysia were also integrated in the formulation of the questions.

For the data analysis, the aforementioned themes were later coded into eight elements of effective campaign planning; namely situation analysis, objectives, audience, strategy, tactics, timeline, budget, and evaluation. From these eight elements, the study then included emergent subcodes that provided a more elaborate interpretation on the already 
outlined themes. The coding process was implemented using the Computer Assisted Qualitative Data Analysis Software (CADQAS), Atlas.ti (version 8) to organise the data collected and to facilitate the overall analysis. Aside from transcripts obtained from the interviews, richness of the data in terms of speech patterns, repetitions, vocal intonations, and accuracy which provide crucial interpretation in order to confirm the saturation of the data obtained was also observed.

\section{FINDINGS}

Based on the co-occurrence analysis that was run using Atlas.ti, it was discovered that three themes emerged as the most frequent across the five interview transcripts; conversation (37 quotations), conversation/connectedness (30 quotations), and participation (28 quotations). Examining across the eight elements of campaign planning, seven elements acquired highest coding; situation analysis (14 quotations), objectives (19 quotations), strategy (15 quotations), tactics (13 quotations), timeline (14 quotations), budget (8 quotations), and evaluation (8 quotations).

The data was later subcoded into keywords for discussion; which are manpower, contents, skills, expenditure, process, report, tools, and recognition. These manifested keywords highlighted the frequency which demonstrate the level of extensiveness in all three themes and further assisted in summarising the context and discourse. These sub-coded matrixes were later tabulated in terms of its frequency to illustrate the most common to the least common quoted genres; content (19 quotations), manpower (17 quotations), skills (9 quotations), social media (7 quotations), process and expenditure are both tied with 6 quotations, tools (4 quotations), while report and recognition only resulted with 3 quotations. Table 1 below provides the abstraction process of the thematic analysis using the matrix of deduction approach.

Table 1 Abstraction Process of Thematic Analysis

\begin{tabular}{lll}
\hline Themes & Code & Sub-code \\
\hline Conversation & & Content \\
& Objectives & Manpower \\
\multirow{4}{*}{ Conversation and } & Situation Analysis & Skills \\
Connectedness & Tactics & Social Media \\
& Timeline & Process \\
& Budget & Expenditure \\
Participation & Evaluation & Tools \\
& & Report \\
& & Recognition \\
\hline
\end{tabular}

The findings further enforced the notion that three main attributes (content, manpower, skills) are crucial for effective social media campaign. Although the remaining attributes remain realistically low in the perception of the officials from MOYS, it does not mean that it is less important. For example, the perceived ideas that report is less important for healthy lifestyle campaign in social media is cautiously risky as report from previous studies could provide an essential know-how on the demographics, content, and skills needed to run a social media campaign. 
For conversation and its importance in promoting healthy lifestyle through social media, the discussion pertaining to FIT Malaysia content mainly revolved around how such postings initiate conversation and participation among social media users across platforms on FB and Twitter. To maximize effectiveness, communicators may want to have a source that is both attractive and credible, but sometimes that combination is not possible (Wilson, 2007). The idea behind the content too is significantly tied to the cause and its effect which creates ripple and viral effects that eventually get people to start talking about it virtually as stated by the interviewee 1 from CCU;

"...social media... because what I meant by wave is by hashtag... with our apps... so... you can't but not hear about our event. No matter how lazy you are to sport... everyone is talking about it, no matter how lazy you are. And you will be hearing that at least one month before the event, leading up to the event..." - Interviewee 1

Similarly, conversation and connectedness showed similar sentiments as far as the content is concerned whereby the interviewee 2 at CCU too mentioned that as a result to the effectiveness of the content creation, the feedback either from the ministry or its followers could serve as a strategy to ensure the conversation stay alive. This is especially significant as the conversation arises from the given feedback could benefit not only those involve, but the general public too could gain more information as it was discussed in a public domain and readily available on the updated timeline.

"...there are several channels how our customer and our external they do can send their complaints to us. So, firstly, they can use our internal website. Secondly, they can use Facebook, Twitter by DM us. And thirdly, they can send directly email to us. So, any complaints as I mentioned before, we will try to answer within 3 working days. Maximum 7 working days..." - Interviewee 2

Meanwhile in participation, interviewee 3 from DYS highlighted that it is important to note that reasons for organisation creating social media page for its programme is to disseminate information online and to achieve favourable image of that particular programmes, products, or services; in this case, FIT Malaysia. The online perception is important as it will contribute to the decision process of whether to take part in the actual event or not.

“...in terms of Fit Malaysia ... aaa... branding is considered a new brand when it is memorable and they aaa... know people want to be fit... so they go direct to aaa... what was the person's objective and goals when we say fit in people's minds it about losing weight and all but when it comes to a fit Malaysia we are not aware that being fit also can lose weight..." - Interviewee 3 
This is a testament to the early stage of the modification of behaviour; from cognitive awareness to modification of behaviour. This is paramount with the assistance of effective social media promotion that provide the much needed social intervention to youth. As posited in the social marketing theory, the receiver (MOYS) must be able to craft an effective message, not only to create awareness but most importantly allow for the recipient (youth) to understand, learn, and more importantly engage with the source through various available platform.

The linkage that manpower has with content signifies the determinant in the success of healthy lifestyle campaign in social media targeting youth segmentation to create the conversation elements that fit in the social media characteristics. Across the three themes, there were 17 quotations that exhaustingly marked the importance of manpower threading in all 7 coded items (Public Relations campaign planning) as well. Apart from the existence of dedicated team in two departments that work together in promoting FIT Malaysia, the team are also tasked to ensuring all the cyber-quackery are dealt with as stated by the interviewee 4 at DYS, MOYS.

"...there is in the department of sports, also in CCU, we use what is readily available. (R: in DYS, your department has one too?). Under the national youth and sports department also we have 3 sections, an officer in charge to entertain social media parts, any inquiries, and to ensure providing of accurate answers and facts we would need to look into it, and we have to answer questions, comments or complaints..." - Interviewee 4

To this, the interviewee 3 at DYS stated that the minister's office hired consultant to design and produce collaterals for FIT Malaysia which include the social media reach. The appointed consultant's task also encompassed on-site programme and integrared marketing communication plans throughout the implementation of FIT Malaysia campaign. Interviewee 1 added that MOYS through the minister's office decided to engage public relations industry experts due to the fact that the ministry is not equipped with sufficient staff who are skillful in marketing and developing strategic healthy lifestyle campaigns.

While the hiring processes was executed by the minister's office, the key stakeholders to ensure the whole concept and ideas of FIT Malaysia accepted by youth is closely monitered by the FIT Malaysia secretariat. The CCU and DYS which made up the secretariat are responsible for posting and corresponding activities; online and offline while the planning part was handled by the minister's office and the appointed consultant.

Officer 2 then added that the entire marketing and promotion strategies for FIT Malaysia is a collaborative effort between the consultant and ministry's officials. It means that while the consultant is responsible on the overall design and production, the FIT Malaysia secretariat was actively involved in the idea, concepts, and philosophy of the overall FIT Malaysia's outlook.

"...in terms of the management of this programme, it is being handled by the consultant. In planning aspects.... Planning to decide policies, then to gain participation ..." - Interviewee 2 
"...we would normally prepare (the ideas for content) ... and most of it comes from our officers here... which include officers from the Minister's office... and all of these ideas came from these offices (Minister's officer, DOYS, CCU) ... most of it (before further discussions with the consultant) ..." - Interviewee 2

“...previous minister... Khairy Jamaluddin... he wants thing... he wants comms specifically ... to be made more the corporate way... so that was his dream when he brought me in. he wanted comms to be run more like... the corporate style rather than the conventional way of government running (event) comms... events and everything-lah..." - Interviewee 1

"...the consultant suggests from that aspect, such as designs, wordings, and the whole lot is determined by them (R: from the minister's side) the minister's side like us administer and manage..."-Interviewee 3

Meanwhile in conversation/connectedness theme, the importance of manpower is apparent when planning for human resources and job responsibilities. It is crucial to ensure consistency and effectiveness of tasks and avoid redundancy especially when two departments are handling FIT Malaysia campaign and this was highlighted by the top officials of the MOYS, the interviewee 4 of DYS himself. This will ensure effective conversation and two-way communication, the tasks are divided to and among several departments; corporate communication, youth and sports division, state level department, and the minister's office. These departments/divisions collaborate in manpower planning, content development, design and assigning correspondence with its public.

"...both parties (R: oh, ok), at one side is from us the Ministry of Youth and Sports, where we have the development of youth and sports department, so, under the sports development we have a dedicated FIT Malaysia secretariat, which is headed by our fitness division that cater to all fitness related programmes. Then, (erm...) it goes to state level..." - Interviewee 4

As for the third theme, participation can be referred strictly to its core definition as one of the social media characteristics that empower the healthy lifestyle campaign that embed the importance of sender in its users' minds. When the participation of users is not reflecting in patterns on social media, nor it is timed, it is difficult to predict the responses or intended perception towards the activity. This was echoed by the administrator of the MOYS social media page for FIT Malaysia that the reasons to participate in any social media is enhanced by the availability of manpower to monitor it, of which insufficiently lacking as admitted by the administrator.

"...there are 4 people. One female and three males that handle the Facebook (account)..." - Interviewee 5 
Additionally, interviewee 1 also added that while the appointed personnel might not have the right academic background, the officer should be able to supplement it with working experiences in the public relations industry, collaborate with youth as well as create mutual interest on social media engagement. It would also be an added advantage if the officers came from the same demographic group of the target audiences; youth where better engagement could be achieved since they speak the same language. All of these attributes would certainly assist MOYS and the FIT Malaysia secretariat to achieve its objectives.

"...The one heading the social media is comms trained. He happens to be having degree in communication, he's currently doing his master in communications. Aaa... but by virtue of his scheme, he's not scheme Penerangan, he actually Belia dan Sukan. His service scheme is Belia dan Sukan. Aaa... I took him in because he's comm trained and... and he has great passion on comm. Prior to joining the ministry as pegawai Belia dan Sukan, he was working in corporate sector doing comms in couple of places..." Interviewee 1

Evidently, it boils down to skills that the officers have to ensure effective content and dissemination of it through social media platforms aims at youth in order to promote healthy lifestye. Interviewee 1 of CCU made it abundantly clear the his staffs must be equipped with the appropriate know and know-how when dealing with social media platform. He also stressed that in continuation to the strategy, the tactics employed to supplement the weaknesses of the staff in communicating effectively, they are sent for training to harness skills and knowledge.

“...I also have officers who are not communication trained at all. Aaa... one of my officers is sports science graduate. Aaa... who is also youth and sports officer taking care of Rakan Muda. But, the reason why I took a certain person in because I believe up to certain level, communication can be trained. Aaa... communication function, communication knowledge, communication skill aaa... can be trained. Some is in you naturally, you just have to grow and nurture them..." - Interviewee 1

The conversation/connectedness too illustrate the relationship when weighing the manpower and skill sets and the Corporate Communication Officer at CCU highlighted that skills and experiences made up the valuable tactics when communicating with youth online. This has also been aptly recommended by interviewee 1 that it is crucial to have the suitable officer in the right position especially when there are various social media platforms available to be used when planning for engagement with youth online. Equipped with social media skills, the officers in charge would be able to harness the various functions available on each social media platform to his advantage where conversation could be further enhanced and expanded. With user generated content and immediate postings, healthy lifestyle campaigns such as FIT Malaysia would be able to reach online youth at greater distance within a short amount of time. 
"...that team? (Yes, the social media). That team that I have is being headed by one officer aaa... he's a comms trained person (ok) aaa... young guy. So... aaa... and he's personally is very active in social media. So... aaa... for KBS it's so interesting that uhmm... I think KBS is the only ministry..." - Interviewee 1

With such speed and tenacity that social media offers, it is almost certain that error and mispostings would occur and this pose significant challenges to the MOYS and FIT Malaysia brand in its entirety. This is because when wrong information is posted by authorities, it reflects the sentiments of people's perception on the level of professionalism of its officials. The damage could be disastrous if it is not handled swiftly. In the case of FIT Malaysia, interviewee 5 spoke at length about it when postings or announcements had been mistakenly posted, the administrators clicked on likes at inappropriate pages or even commented on negative postings. When this happened, it would be immediately rectified; either by the officer or through the superiors that keep a second set of eyes in monitoring the postings. The participation of more than one administrator in handling the FB and Twitter account for FIT Malaysia would ensure that while the presence remains active, the passive administrator acts as feeder to correct the misinformation posted by another team online. A crossover between conversation and connectedness allow the user to interpret healthy lifestyle information in a more holistic way.

"...I once unintentionally 'liked' (okay) on Twitter, when we use the search function, mistakenly 'liked' on Twitter, haa... that I experienced (oh) because a person (used) used handphone (MOYS official handphone?) because at the time I was looking for issues if MOYS had any (right, right), then someone advised me against it (it unintentional right, then I 'unliked' it) unliked it (that's it right?) no problem (okay from the aspect of...) if posting, never did, I never was posted an error..." - Interviewee 5

\section{DISCUSSION}

Evidently, there is a need for health communication campaigns to utilise organised mixed media methods to generate change and adapt behaviour towards specific outcomes in targeted individuals (Atkin \& Salmon, 2010; Weiss \& Tschirhart, 1994). In the social media realm and in the case of FIT Malaysia, the user-generated content that was embedded in FB and Twitter allowed for immediate response to any posting related to healthy lifestyle and its ensuing programmes. While the responses were encouraging from audiences, there is no certain measurement or tool that is dedicated to benchmark audience participation with the campaign. The consistency of campaigning for firms and authoritative bodies over social media towards youths and their ability to interpret the data or content cannot sustain beyond peer engagement and informal discussions on networking platforms. There needs to be much intervention and proactivity from firms and authoritative bodies to build their reputation with communities both online and offline that complement each other in the long term. Henceforth, the inclusion of youth in any programme is imperative for the sustenance of rapid development and good governance from the government as well as other stakeholders. The fact that $80 \%$ of Malaysians seek information through online networking 
to understand new trends and cultural practices in newsfeeds, status updates and captioned images sees great potential and outcomes of the FIT Malaysia initiatives (Hearn \& Schoenhoff, 2016; Malaysian Communications and Multimedia Commission, 2017).

This is further strengthened by the fact that sufficient manpower is needed for FIT Malaysia to reach out to more than 21 million youth in Malaysia, especially in maintaining its online presence. Despite there being two departments promoting FIT Malaysia, it was also mentioned that the minister himself (former MOYS Minister, YB Khairy Jamaluddin) took special interest in promoting FIT Malaysia but the coordination between departments and participating departments or bodies are still in need of improvement.

Shenai (2011) argued that it is challenging for media planners to gauge participation of a brand's target audience as no content or data is available to formulate a new viral campaign. The human capital in the respective department must be able to emulate existing or past viral campaigns, build content on the lines of such successful articles and most importantly contribute to the overall objective of the campaign itself. This would mean that there should be stringent monitoring and archiving of data to predict and formulate forms of engagement with the existing and growing youth audience. Without such monitoring, the campaign initiatives would weaken and social media would not be as effective to reach the youth cohort due to lack of engagement. The notion of skills in ensuring fruitful conversation that educate the youth through online postings are as important as spending millions of taxpayers' money organising FIT Malaysia programmes on the field.

Additionally, when discussing campaigns and associated theory, Andreasen (1994) provided distinct classifications that social advertising is synonymous with campaigns and its relationships with programmes. While campaigns have a fixed termination point, programmes, by contrast, may last decades and contain several campaigns within them. Thus, with close relation to healthy lifestyle campaign like FIT Malaysia, the American Cancer Society as pointed by Anderson, has a similar long-run social marketing program to reduce the incidence of smoking. An important strength of social marketing is that it takes a programmatic rather than campaign view of its mission and interestingly, social marketing is widely used to influence social behaviour.

\section{CONCLUSION}

As social media is currently driving marketing and branding for large organisations and bridges the gap between them and their audiences, the unique structures and functions of networking platforms, as has been deployed by FIT Malaysia should continuously provide conversational currencies and incite an exciting communal experience for youths. ChanOlmsted, Cho and Lee (2013) in earlier studies highlighted that campaigns using social media should look into allocating sufficient resources to achieve the desired objectives and synergy among the content providers or producers. Considering that the campaign is targeted to connect with a massive number of Malaysian youths aside from the overall Malaysian population, the heavy user groups should be able to visit an approachable and consistent site that provides an ever-ready linkage to information that not only underlines the campaign aims but also provide opportunities for networking, camaraderie, companionship and physical participation in ongoing programme initiatives that encourage active engagement of the users, while at the same time sustaining the positive affirmations of youth audiences towards organisations or governing bodies such as MOYS. Dominick (2013) aptly stated that 
mass media do not supply just facts and data. They also provide information on the ultimate meaning and significance of events and (media) organisations must be able to select those events that are to be given time or space and decide how much prominence they are to be given. To move forward, research on audience feedback and perceptions on health-related campaigns could provide more insight to the success of effective campaign implementations on such social media spaces.

\section{BIODATA}

Suffian Hadi Ayub is a senior lecturer at Department of Communication, School of Arts, Sunway University and PhD candidate at Universiti Teknologi MARA, Shah Alam, Malaysia. Email: suffianay@sunway.edu.my

Nurzihan Hassim is a senior lecturer at Taylor's University, Malaysia. Email: zihan@taylors.edu.my

Azizul Halim Yahya is a Professor and Dean at Universiti Teknologi MARA, Malaysia. Email: azizul@salam.uitm.edu.my

Massila Hamzah is a senior lecturer at Universiti Teknologi MARA, Malaysia. Email: massila@salam.uitm.edu.my

Mohd. Zamri Abu Bakar is a PhD candidate at Universiti Teknologi MARA, Malaysia. Email: zamrimfs@yahoo.com 


\section{REFERENCES}

Alaniz, L. (2012, January 10). The eight basic elements of a PR plan. Retrieved from http://luisrocks.com/blog/the-eight-basic-elements-of-a-pr-plan/

Andreasen, A. (1994). Social marketing: Its definition and domain. Journal of Public Policy \& Marketing, 13(I), 108-114.

Atkin, C., \& Salmon, C. (2010). Communication campaigns. In C. Berger, M. Roloff, \& D. Roskos-Ewoldsen (Eds.), The handbook of communication science (2nd ed., pp. 419436). London: SAGE Publications.

Baboo, S. B., Pandian, A., Mustafa, M., Backer, M. B., \& Ilangko Lim, J. Y. S. (2015). Captivated with Facebook: Constructions, contexts and consequences. In Malaysian Communications and Multimedia Commission (Eds.), Networked media content research summary (Vol.2, pp. 9-12). Selangor: Author. Retrieved from https://www.mcmc.gov.my/skmmgovmy/media/General/pdf/Network-MediaContent-Summary-Volume-2.pdf

Boyd, D. (2014). It's complicated - The social lives of networked teens. New Haven London: Yale University Press. doi: 10.1039/b916505n

Calin, R. A., \& Birsanescu, I. A. (2017). Young Romanians'" digital natives", social media and self-branding. Elearning \& Software for Education, 1.

Castells, M. (2011). The rise of the network society (Vol. 12). NJ: John Wiley \& Sons.

Chan-Olmsted, S., Cho, M., \& Lee, S. (2013). User perceptions of social media: A comparative study of perceived characteristics and user profiles by social media. Online journal of communication and media technologies, 3(4), 149-178.

Dominick, J. (2013). The dynamics of mass communication: Media in the digital age (12th ed.). New York: McGraw-Hill Higher Education.

Economic and Social Commission for Asia and The Pacific. (2002). Youth in Malaysia: A review of the youth situation and national policies and programmes. NY: United Nations.

Ellison, N., Steinfield, C., \& Lampe, C. (2007). The benefits of Facebook "Friends:" Social capital and college students' use of online social network sites. Journal of ComputerMediated Communication, 12, 1143-1168.

Fernández-Cruz, F. J., \& Fernández-Díaz, M. J. (2016). Generation Z's Teachers and their Digital Skills: Los docentes de la Generación $Z$ y sus competencias digitales. Comunicar, 24(46), 97-105.

Gardner, H., \& Davis, K. (2013). The app generation: How today's youth navigate identity, intimacy, and imagination in a digital world. Connecticut: Yale University Press.

Go-globe. (2015). Social media usage in Asia Pacific - Statistics and trends. Retrieved from http://www.go-globe.com/blog/social-media-asia/

Hassim, N. (2017). Hijab in the city: Discursive representation of female modesty in selected contemporary Malaysian media. Kuala Lumpur: University of Malaya.

Hajli, M. N. (2013). A study of the impact of social media on consumers. International Journal of Market Research, 56(3), 387-404. doi: 10.2501/IJMR-2014-025

Heverly, R. A. (2008). Growing up digital: Control and the pieces of a digital life. Digital Youth, Innovation, and the Unexpected, 199-213. doi: 10.1162/dmal.9780262633598.199

Jack, S. (2010). Approaches to studying networks: Implications and outcomes. Journal of Business Venturing, 25(1), 120-137. 
Kemp, S. W. A. S. (2017). Digital in 2017: Southeast Asia. We are social. Retrieved from http://www.slideshare.net/wearesocialsg/digital-in-2017-southeast-asia

Kim, A. J., \& Johnson, K. K. P. (2016). Power of consumers using social media: Examining the influences of brand-related user-generated content on Facebook. Computers in Human Behavior, 58, 98-108. doi: 10.1016/j.chb.2015.12.047

Lai, C., Altavilla, D., Ronconi, A., \& Aceto, P. (2016). Fear of missing out (FOMO) is associated with activation of the right middle temporal gyrus during inclusion social cue. Computers in Human Behavior, 61, 516-521. doi: 10.1016/j.chb.2016.03.072

Malaysian Communications and Multimedia Commission. (2017). Internet users survey 2017: Statistical brief number twenty-one. Malaysia: Author.

Mayfield, T. (2011). A commander's strategy for social media. JFQ, 79-238. Retrieved on February 8, 2019, from https://www.marketingoops.com/media-ads/socialmedia/what-is-social-media/

Mueller, J., , K., Fueller, J., \& Matzler, K. (2011). Virtual worlds as knowledge management platform - A practice-perspective. Information Systems Journal, 21(6), 479-501.

Newman, N., Fletcher, R., Kalogeropoulos, A., Levy, D. A. L., \& Nielsen, R. K. (2017). Reuters institute digital news report 2017. Reuters Institute.

Shenai, T. (2011, May 22). Social media contribution participation and future. Social Mdia Today. Retrieved from https://www.socialmediatoday.com/content/social-mediacontribution-participation-and-future

Sundar, S. S., \& Limperos, A. M. (2013). Uses and grats 2.0: New gratifications for new media. Journal of Broadcasting \& Electronic Media, 57(4), 504-525. doi: 10.1080/08838151.2013.845827

Sunway University. (2015). Unveiling Online Perception toward "1Malaysia" Over Time: A Social Impact Analysis. In, Networked Media Content Research Summary (Vol.2, pp. 13-17). Selangor: Malaysian Communications and Multimedia Commission. Retrieved from https://www.mcmc.gov.my/skmmgovmy/media/General/pdf/Network-MediaContent-Summary-Volume-2.pdf

United Nations. (2008). Definition of youth. Retrieved from http://www.un.org/esa/socdev/documents/youth/fact-sheets/youth-definition.pdf

Weiss, J., \& Tschirhart, M. (1994). Public information campaigns as policy instruments. Journal of Policy Analysis and Management, 13(1), 82-119.

Wilson, B. (2007). Designing media messages about health and nutrition: What strategies are most effective?. Journal of Nutrition Education Behavior, 39, S13-S19.

Yuksel, M., \& Labrecque, L. (2016). "Digital buddies": Parasocial interactions in social media Mujde. Journal of Research in Interactive Marketing, 10(4), 305-320. doi: 10.1108/01437720410560451 